\title{
Research and Development of Cultural Sharing Space in Economically Underdeveloped Areas
}

\author{
Lu Liu \\ Department of Design, Lanzhou University of Technology, Lanzhou, Gansu, China \\ *Lu Liu.Email: 1525307045@qq.com
}

\begin{abstract}
People's demand for spirit and culture shows a trend of rapid growth under the huge background of the current rapid economic development in China. Cultural sharing space has played an important role in people's economic life, cultural exchange and interpersonal interaction. But at present, due to the imbalance of domestic economic development, cultural sharing spaces in economically underdeveloped areas are generally in a state of lack. This paper takes the development of cultural sharing spaces in economically underdeveloped area (Baihe County, Shaanxi Province) as the break point to explore the development ways of cultural sharing spaces in Baihe County through field investigations and related literatures research. The results show that the construction of cultural sharing spaces in economically underdeveloped areas is an inevitable trend, and it is an important method to promote regional economic growth, achieve sustainable development and meet the spiritual needs of the people.
\end{abstract}

\section{Keywords: Sharing space, Culture, Economy}

\section{INTRODUCTION}

Mobile Internet and sharing economy has changed people's lifestyles at an unexpected speed. Sharing space is created under this background. The so-called sharing space generally refers to a public building space that is used by the public, which is a kind of architectural space created by American architect John Portman in the 20th century according to people's cognition and psychological reaction to the environment. One of the main meanings and functions of sharing space is to meet people's different psycholgical needs for the environment and promote people to communicate to a greater extent.

\subsection{Research Background And Sgnificance}

\subsubsection{Research Background}

[1] With the development of economy, people's demand for culture also shows a gradual increase trend. Just as Abraham Maslow divided human needs into five levels, it is clear that most people in today's society are no longer just satisfied with the level of biological needs, but pursue the level of self-realization. In this context, it highlights the necessity of cultural sharing space. Cultural shared space is an organic combination of social, spiritual, and physical spaces. People rely on this space to communicate and interact to meet their own cultural and spiritual needs. However, the research shows that China's cultural industry is still in the early stage of development, and the unbalanced spatial structure of the cultural industry is positively correlated with economic development -- the developed cities in the east are strong and the underdeveloped areas in the west are weak. What's more, the imbalance of urban and rural cultural products consumption is also concentrated in the economically underdeveloped areas. [2] Well, the adversity of cultural fragmentation, marginalization and passivity in underdeveloped areas is closely related to the lack of cultural sharing spaces.

Taking Baihe County in Shaanxi Province of China as an example, which is located in the depth of a mountain on the border of Shaanxi Province and Hubei Province of China. It is a typical mountainous county, and it is also a typical deep poverty county in China before 2020 . Although it has a poor background, Baihe county has rich cultural heritage, such as folk music (Baihe county formed folk tunes, dance songs, haozi, and a complete set of percussion music in the late Qing Dynasty and the early Republic of China), folk art (especially good at carving, which can be divided into wood carving and stone carving), folk dance, etc; In addition, Baihe county also has rich tourism resources, such as Baihe stone Great Wall site, Zhangjia courtyard, Qiaoergou and other 
ancient relics sites. But due to the economic, geographical location, transportation and other reasons, coupled with the lack of local public cultural space, the excellent traditional cultural resources of Baihe county have not been fully developed and utilized, and the cultural life form of local residents is single. There are many cities such as Baihe county. It is an urgent problem to protect the local culture and meet the cultural needs of local residents.

\subsubsection{Current Research Status Of Sharing Space In Abroad}

Sharing space is a new service concept that emerged in the United States in the 1990s. Its general expressions include knowledge sharing space, learning sharing space, and information sharing space. After more than 20 years of development, to this day, many public spaces have been created at home and abroad, and their service models have changed. For example, Club Workspace in London is a kind of co-working space, with 10 office spaces on the banks of the Thames and London Bridge. Compared with other co-working spaces, its office space is more formal, providing individual or start-up enterprise with lockers, meeting rooms or event spaces. Another example is the project of Polytechnic University of Milan -- the social vegetable garden (coltivando), which mainly explores two important themes in Milan: the first is how to reconstruct the public cultural activities and spaces of the community residents through design and intervention; the second is how to better design and build an energy and food security supply management system for the entire Milan area. This project opens the public activity space on the campus of the Design School of Polytechnic University of Milan for free to Milan citizens living around the design school community, and guides them to re-use this public space resources, planting and nurturing all kinds of fruits and vegetables that meet the needs of the common development of the community. Then develop it into a public activity platform for community residents to communicate with each other, learn together and collaborate, and strive to make this undeveloped and used public space create greater social and economic value.

\subsubsection{Current Research Status Of Sharing Space In China}

Let's look at the current situation of the development of sharing space in China: research shows that in recent years, the public office spaces in the first batch of cities in China have developed rapidly, with nearly 300 sharing office brands emerging, such as Honeycomb , Wstudio, etc., and even emerged as a leading enterprise, Youke Workshop. After We Work settled in Shanghai, Hong Kong and Beijing, now it has eight office buildings in China. Refer to the We Work model, many shared office spaces have sprung up in China, and they have developed rapidly. [3] Another example: In Siping Road Community, Yangpu District, Shanghai, China, two-thirds of residential communities were built in the 1980s. With the development of decades, houses and facilities have become old. Such residential communities have gradually become a part of restricting the economic development of Shanghai. While in recent years, the social innovation activity -- "Open Your Space" jointly initiated by Tongji University's College of Design and Innovation (D\&I) and Siping Road Street, Yangpu District, Shanghai, China has changed the public activity space of Siping community dramatically. In addition to the unique and creative graffiti walls drawn by community residents, public children's playground facilities, it also have irregular artists' activities, etc. After the teachers and students of the D\&I shared their creative creation with surrounding community residents, the originally dirty and disorderly public space not only gradually transformed into a platform for the transformation of educational and scientific research achievements of Tongji University, but also a shared activity space for community residents around Tongji University to visit and relax, enriching the lives of community residents.

These examples show that the development of China's domestic sharing space is showing a good momentum, and they have important reference value for the future development of China's sharing space.

\subsubsection{Research Significance}

[4] In the context of rapid social economic growth, some sharing service spaces in old urban communities can no longer meet people's living needs, so the upgrading of urban public service spaces based on the sharing economy model has become an inevitable trend. In economically underdeveloped areas, the problem presented is not only the inability of the old sharing service spaces to meet people's demand, but the bigger problem is the lack of shared cultural service spaces. While as an important space for interpersonal communication among community residents and a carrier of regional cultural inheritance, cultural shared space is an important way to develop the cultural structure of economically underdeveloped regions. [5] Whether in developed or underdeveloped areas, public cultural space has a close relationship with public life, and it has a significant influence on the development of culture. Therefore, in underdeveloped areas, cultural reconstruction should start from the development of public cultural space and the reconstruction of public cultural life.

This research takes Baihe County, Shaanxi Province as an example, to meet the needs of local residents' cultural life and promote local excellent traditional culture as the purpose to design the space. The aim is to differentiate the functions of the space so that make the 
space has different functions. Satisfying and enriching the cultural life of the residents of the community, and the residents can read books, experience science and technology, listen lectures and other activities here. In addition, empower the local residents to become "managers" of the sharing space, they can explain to the visitors and become disseminators of the local culture.

\section{RESEARCH CONTENTS AND KEY ISSUES TO BE SOLVED}

\subsection{Research Contents}

Due to various reasons such as economic backwardness, complex terrain, and traffic obstruction, Baihe County provides very few cultural sharing spaces for community residents. There is even a leisure plaza in the center of the city for residents to entertain, not to mention the surrounding areas. In towns, there is almost no development of cultural sharing spaces. Through the later summary of the questionnaire, it was found that the residents of Baihe County rarely engage in cultural activities in their leisure time. When asked about the construction of a shared cultural space, the residents agreed very much. This research is based on the construction of the cultural shared space in Baihe County, so that enrich the public cultural life of the residents of Baihe County, strengthen the bond between community residents, and promote the excellent traditional culture of Baihe County through the design of the interior exhibition hall of the space.

\subsection{Key Issues To Be Solved}

After the previous field visit to Baihe county and the understanding of the current situation of the research on the shared space at home and abroad, the author has a certain understanding of the problems that need to be solved in the construction of cultural shared space. The problems to be solved in this design plan are generally as follows: The first is the linkage between the overall space design and local culture; the second is to meet the multifunctional needs of local residents for space, such as quiet reading, technological experience, leisure and entertainment, cultural exhibitions, daily lectures, etc.; the third is to optimize the internal layout of the space and the flow of people on the basis of meeting the basic functions of the space, so as to achieve flexible movement and reasonable organization of the flow of people, and prevent retrograde due to the design of the movement or hindrance.

\subsection{Research Methods And Framework}

\subsubsection{Research Methods}

The design plan is mainly aimed at how to effectively combine the shared space and multiple functional spaces.
Through field research, the author deeply studied the local traditional culture of Baihe County, such as the local ancient architecture culture, wood carving, and family discipline culture, etc. The cultural exhibition space is combined with the modern multifunctional sharing space, turn the space into the material carrier that can repose emotions.

\subsubsection{Research Framework}

1. Explore the extraction of the theme elements of the space, what types of local cultural elements are suitable for the construction of the space and can be integrated with the surrounding environment; 2. Visualize the extracted elements; 3 . According to the space's different internal functions, divide the interior of the space; 4 . Planning the public space outside the entire building to meet the needs of residents to a greater extent.

\section{SPACE DESIGN ANALYSIS AND APPLICATION}

\subsection{Design Goals}

The design plan comes from thinking about the development status of shared cultural spaces in economically underdeveloped areas. Most of these areas lack cultural innovation and vitality, and the contradiction between cultural supply and demand is very prominent, all of which have severely restricted the development and construction of the region. While this kind of contradiction does not appear temporarily, but is caused by the long-term unbalanced development between regions, but this kind of contradiction can be weakened or changed. Taking Baihe County as an example, through the study of the local traditional culture of Baihe County, can make the cultural sharing space and the exhibition space organically combined to meet the cultural needs of residents, strengthen emotional exchanges between residents, and promote the excellent traditional culture of Baihe County to local tourists. So that it can become a landmark architectural space in Baihe County.

\subsection{Design Contents}

\subsubsection{Spatial Function Analysis}

The interior of the space is divided into four parts: service reception, cultural display, leisure and entertainment, and technological experience. When designing, pay attention to the local traditional culture of Baihe County and integrate its cultural elements into the exhibition hall. Through the construction of the scene, in addition to receiving tourists in the first space, visitors can also understand the overall layout of the space in advance; in the second space, the family discipline culture of Baihe County is integrated. And Baihe carving, paper-cutting, shadow puppets and other traditional 
cultures are displayed, so that visitors can have a deeper understanding of Baihe culture; the third exhibition hall is mainly set up with functions such as reading, handicraft experiences, lectures, etc., to meet the cultural needs of local residents in Baihe County; the fourth exhibition hall is targeted at the audience of local youth groups, enabling them to broaden their horizons and experience the charm of modern technology.

\subsubsection{Spatial Streamline Analysis}

The moving line of people in the space presents a single linear state, with entrances and exits set in the first hall and the fourth hall respectively, and the moving line of the whole space is in series.

\subsubsection{Spatial Color Analysis}

Because most of the traditional buildings in Baihe County use wood materials, so a large number of woods are used in the space, and the wood color of the space can give people a warm and feeling. In the design of the third hall, considering that the crowd will be young people, a small amount of green and yellow are added to the color of the space to complement the wood color, so that make it does not monotonous.

\subsubsection{Space Lighting Analysis}

As the whole space adopts a large number of glass curtain walls, and skylights are opened on the top of the second hall and the third hall, so the whole space has sufficient lighting, and generally does not need special lighting design. While in the second Hall of the display cabinets using sheet lamp for lighting, and use spotlights for lighting on the second floor with poor lighting of the third hall.

\subsubsection{The Use Of Science And Technology In Space}

The application of modern science and technology also plays a vital role in space design. In this space design, many places have adopted new media technology. For example, self-service information inquiry when entering the space, and a guided tour of the entire space; the time passage of the third hall into the fourth hall uses holographic projection technology to enable people to switch scenes; the fourth hall is a space for scientific and technological experience, so make people feel the charm of modern technology and broaden the horizons of local young people.

\section{DISPLAY OF DESIGN ACHIEVEMENTS}

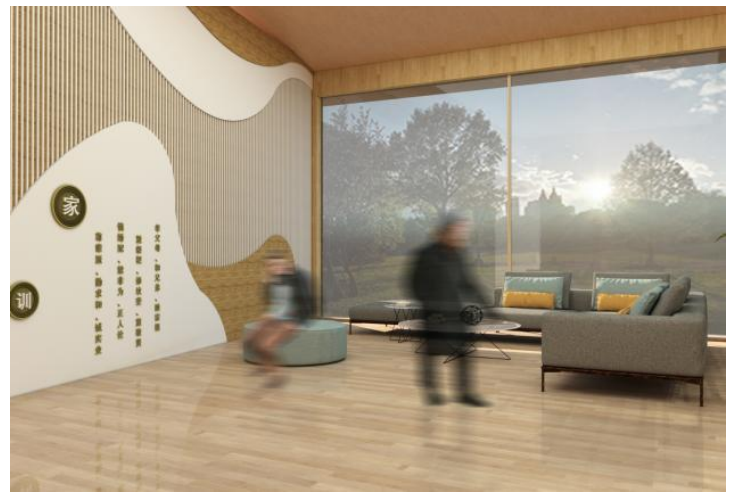

Figure 1 Service reception space

Service guide space, where visitors can know the overall spatial structure in advance and have a rest.

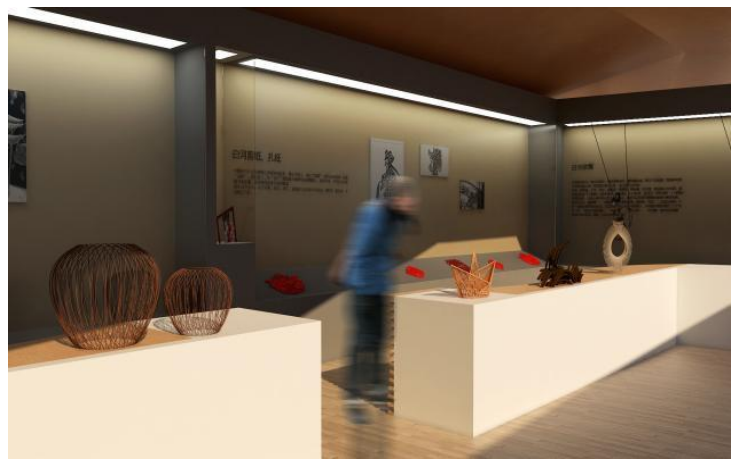

Figure 2 Cultural exhibition space

The cultural exhibition space, where displays the excellent local traditional culture of Baihe County. Tourists can have a good understanding of Baihe culture here.

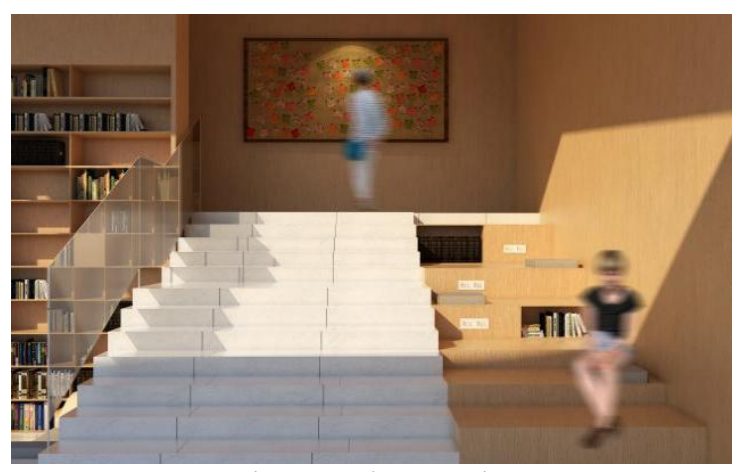

Figure 3 Leisure and entertainment space

Leisure and entertainment space, where community residents can read, listen to lectures, play games, etc. 


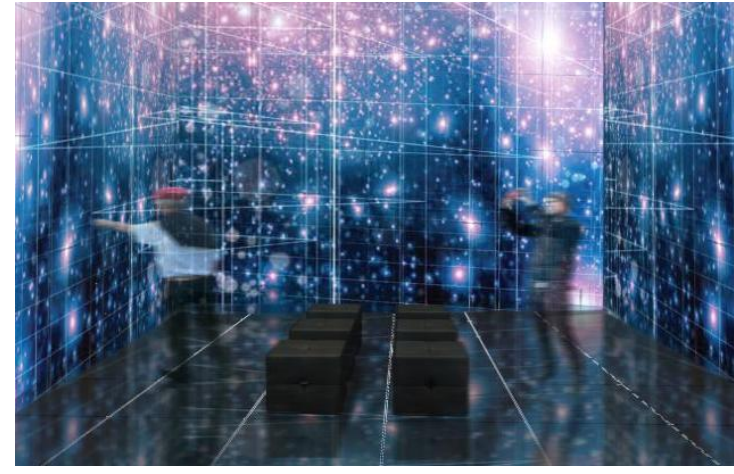

Figure 4 Technology experience space

Science and technology experience space, adding thermal experience and VR experience area to the space, giving people a better experience.

\section{CONCLUSIONS}

[6] Rural revitalization is the China's development strategy and the central point of the China's modernization in the future. Cultural construction is an important aspect of it, and fostering spaces for mass culture is an important way of development. The construction of cultural sharing space can meet the basic cultural life needs of people in economically underdeveloped areas. In addition, the development of culture and economy presents a positive correlation, the growth of regional culture affects the economic growth of a region to a large extent. Therefore, it is an inevitable trend to develop cultural sharing spaces in economically underdeveloped areas.

The design of space has always been a means for people to meet their own needs, thus adapting to the environment and shaping the artificial environment. As a combination of a sharing space and a cultural exhibition space, this design plan is designed based on the current situation of local problems in Baihe County and the needs of the target population. It is hoped that this research can attract more social attention to the lack of cultural sharing spaces in economically underdeveloped areas, then promote the construction and development of sharing cultural spaces in economically underdeveloped areas.

\section{REFERENCES}

[1] Ma, S.H. Public Cultural Service System and Urban Cultural Space Expansion. Fujian Tribune(The Humanities \& Social Sciences Monthly), 2010, pp. 58-61

[2] Zhang, L., Liu, B.Y., Song, Q.Y. A Study of Public Cultural Space Planning in Modern Rural Community: A Case Study of YuJiaBian Village, Jurong City in Jiangsu Province. Journal of Chinese Urban Forestry, 2016, pp. 12-16. DOI: https://doi.org/10.3969/j.issn.1672-

4925.2016.03.003
[3] Lou, Y.Q. NICE 2035: An Experiment of Design Driven Community-supported Social Innovation. Art\&Design, 2018, pp. 34-39. DOI: https://doi.org/10.16272/j.cnki.cn111392/j.2018.05.001

[4] Zhang, L.W., Li, X.X., Wang, Z.Z. Research on the Optimization Strategy of Cultural Space in Urban Old Communities Based on Sharing Economy. Financial Management, 2019, pp. 52-54. DOI: https://doi.org/10.3969/j.issn.16731107.2019.07.029

[5] Ma, Y.Q. The Significance of and Approaches to the Reconstruction of Public Rural Cultural Spaces. Gansu Social Sciences, 2011, pp. 179-183. DOI: https://doi.org/10.15891/j.cnki.cn621093/c.2011.03.041

[6] Chen, B. (2018) The Weakening of Public Cultural Space: The "Soft Underbelly" of Rural Cultural RevitalizationThe Weakening of Public Cultural Space: The "Soft Underbelly" of Rural Cultural Revitalization. People's Tribune, 2018, pp. 124-127. DOI: https://doi.org/10.3969/j.issn.10043381.2018.21.056 